\title{
Metal-on-metal (MoM) hip implants and pregnancy: are MoM implants good for mom? - a systematic review
}

\author{
Linsen T. Samuel ${ }^{1}$, Jacob M. Rabin ${ }^{1}$, Nicholas R. Arnold ${ }^{1}$, Mohammed Munim ${ }^{1}$, Peter J. Brooks ${ }^{1}$, \\ Michael A. Mont ${ }^{1,2}$ \\ ${ }^{1}$ Department of Orthopaedic Surgery, Cleveland Clinic Foundation, Cleveland, OH, USA; ${ }^{2}$ Department of Orthopaedic Surgery, Lenox Hill \\ Hospital, Northwell Health, New York, NY, USA \\ Contributions: (I) Conception and design: LT Samuel, PJ Brooks; (II) Administrative support: LT Samuel, M Munim; (III) Provision of study materials \\ or patients: PJ Brooks; (IV) Collection and assembly of data: LT Samuel, M Munim; (V) Data analysis and interpretation: LT Samuel, JM Rabin, NR \\ Arnold; (VI) Manuscript writing: All authors; (VII) Final approval of manuscript: All authors. \\ Correspondence to: Michael A. Mont, MD. Vice President of Strategic Affairs, Department of Orthopaedic Surgery, Lenox Hill Hospital, Northwell \\ Health, 100 E 77th St, New York, NY 10075, USA. Email: rhondamont@aol.com.
}

\begin{abstract}
Metal-on-metal $(\mathrm{MoM})$ bearing surfaces were historically used for young patients undergoing total hip arthroplasty, and remain commonplace in modern hip resurfacing. A substantial number of female patients with MoM bearings subsequently gave birth following implantation of the bearings before a full understanding of metal ions exposure in these patients was established. In theory, it has been postulated that metal ions released from such implants may cross the placental barrier and cause harm to the fetus. In light of this potential risk, recommendations against the use of MoM components in women of child-bearing age have been advocated. The purpose of this systematic review was to evaluate: (I) the MoM bearing types and ion levels found; (II) the concentrations of metals in maternal circulation and the umbilical cord; and (III) the presence of abnormalities in the fetus or delivered child. A comprehensive literature review was conducted of studies published between January 1st, 1975 and April 1st, 2019 using specific keywords. We defined the inclusion criteria for qualifying studies for this review as follows: (I) studies that reported on the women who experienced pregnancy and who had a MoM hip implant; (II) studies that reported on maternal metal ions blood and umbilical cord levels; and (III) studies that reported on the occurrence of fetal complications. Data on cobalt and chromium ion levels in the maternal blood and umbilical cord blood, as well as the presence of adverse effects in the infant were collected. Age at parturition and time from MoM implant to parturition were also collected. A total of six studies were included in the final analysis that reported on a total of 21 females and 21 infants born. The mean age at parturition was 31 years (range, 24 to 41 years), and the mean time from MoM implantation to parturition was 47 months (range, 11 to 119 months). Maternal blood cobalt levels were found as a weighted average of $34.09 \mathrm{ug} / \mathrm{L}(0.425$ to $138 \mathrm{ug} / \mathrm{L})$, while umbilical cord blood cobalt levels were found to be $22.61 \mathrm{ug} / \mathrm{L}(0.52$ to $51.11 \mathrm{ug} / \mathrm{L})$. Cobalt levels were reduced by an average of $34 \%$ between maternal and umbilical cord blood. Maternal cord blood chromium levels were found as a weighted average of $18.18 \mathrm{ug} / \mathrm{L}(0.225$ to $75 \mathrm{ug} / \mathrm{L})$, while umbilical cord chromium levels were found to be $3.96 \mathrm{ug} / \mathrm{L}(0.14$ to $11.96 \mathrm{ug} / \mathrm{L})$. Chromium levels were reduced by an average of $78 \%$ between maternal and umbilical cord blood. No cobalt or chromium was detected in the umbilical cord blood of three patients. Out of the 21 infants born to women with MoM implants, 20 were born healthy with no adverse effects or complications. vOnly one complication was recorded in single infant that did not appear to be related to the maternal MoM implant. To date, there is a lack of consensus as to whether MoM hip arthroplasty implants are to be avoided in the child-bearing female population and whether they constitute a hazard to the fetus in utero. Both chromium and cobalt ions were markedly reduced in levels when transitioning from maternal to cord blood. In particular, chromium showed a greater reduction on average than cobalt (78\% vs. 34\%). Based on the current evidence, there appears to be no correlation between the presence of metal ions in umbilical cord blood and complications, as none of the infants experienced abnormalities uniquely attributable to the presence of metal ions.
\end{abstract}


Keywords: Cobalt; chromium; hip arthroplasty; implants; pregnancy; metal-on-metal (MoM)

Submitted Jun 20, 2019. Accepted for publication Jul 15, 2019.

doi: $10.21037 /$ atm.2019.07.44

View this article at: http://dx.doi.org/10.21037/atm.2019.07.44

\section{Introduction}

Metal-on-metal (MoM) hip prostheses were used historically in total hip arthroplasty and are still used in hip resurfacing. Despite initial wide spread utilization $(1,2)$, multiple studies have raised concerns about excessive release of metal ions from these prostheses into the systemic circulation along with increased risk of fretting, corrosion, and adverse local soft tissue reactions $(3,4)$. In some reports, it was postulated that pregnant women who have elevated metal ion levels may be at increased risk of mutagenic, teratogenic, or acute fetotoxic effects in their offspring if metal ions crossed the placental barrier (5). In light of this potential risk, recommendations against the use of $\mathrm{MoM}$ components in women of child-bearing age have been advocated (6-9).

Despite the historical practice of using MoM hip implants in women of child-bearing age, there remains a contemporary theoretical dilemma concerning their effect on fetuses of pregnant women who may have undergone MoM-THA or hip resurfacing (6). However, the true clinical importance of elevated metal ion levels in these women remains uncertain. Therefore, the purpose of this systematic review was to elucidate the survivorship associated with MoM implants in gravida women. Specifically, we evaluated: (I) the MoM types and ion levels observed; (II) the presence of maternal and umbilical cord levels of the metals; and (III) the presence of abnormalities in the fetus or delivered child.

\section{Methods}

A comprehensive literature search was conducted of studies published between January 1st, 1975 and April 1st, 2019 concerning MoM hip resurfacing and THA and pregnancy. The following databases were queried: PubMed, EBSCOhost, and EMBASE. The following keywords were used in combination with Boolean operators AND or OR for the literature search; "metal-on-metal," "pregnancy," "hip," "metal ions," "cobalt," "chromium," "arthroplasty," "resurfacing," "arthroplasty," "malformations," and "complications." Inclusion criteria for qualifying studies were defined as follows: (I) studies that reported on the women who experienced pregnancy and who had a MoM hip implant; (II) studies that reported on maternal metal blood levels and umbilical cord metal levels; and (III) studies that reported on the congenital malformation status of the infant. Umbilical cord metal ion levels were determined at delivery. Additionally, we excluded: (I) duplicate studies among searched databases and (II) previous reviews. Data on cobalt and chromium ion levels in the maternal blood and umbilical cord blood, as well as the presence of congenital malformations or other abnormalities in the infant, were collected. Age at parturition and time from MoM implantation to parturition were also collected. The selection process is summarized in Figure 1.

A total of six studies met our criteria (6-11). They reported on twenty-one females with $\mathrm{MoM}$ prostheses, who gave birth to twenty-one infants. The mean age at parturition was 31 years (range, 24 to 41 years), and the mean time from MoM implant to parturition was 47 months (range, 11 to 119 months). All studies prospectively enrolled pregnant patients with MoM implants. Three studies included a control group comprised of perinatal women with no metal implants (9-11). Concentrations of cobalt and chromium in both maternal and umbilical cord blood at parturition were determined in all twenty-one patients utilizing routine methodology previously published on $(12,13)$. All studies evaluated infants for effects of teratogens and general health shortly after birth. Findings from the individual studies are summarized in Table 1.

\section{Results}

\section{Metal ion levels in mothers and infants}

Maternal blood cobalt levels were found as a weighted average of $34.09 \mathrm{ug} / \mathrm{L}$ (range, 0.425 to $138 \mathrm{ug} / \mathrm{L}$ ), while umbilical cord blood cobalt levels were found to be $22.61 \mathrm{ug} / \mathrm{L}$ (range, 0.52 to $51.11 \mathrm{ug} / \mathrm{L}$ ). Cobalt levels were reduced by an average of $34 \%$ between maternal and umbilical cord blood. Maternal cord blood chromium levels were found as a weighted average of $18.18 \mathrm{ug} / \mathrm{L}$ (range, 0.225 to $75 \mathrm{ug} / \mathrm{L}$ ), while umbilical cord chromium 


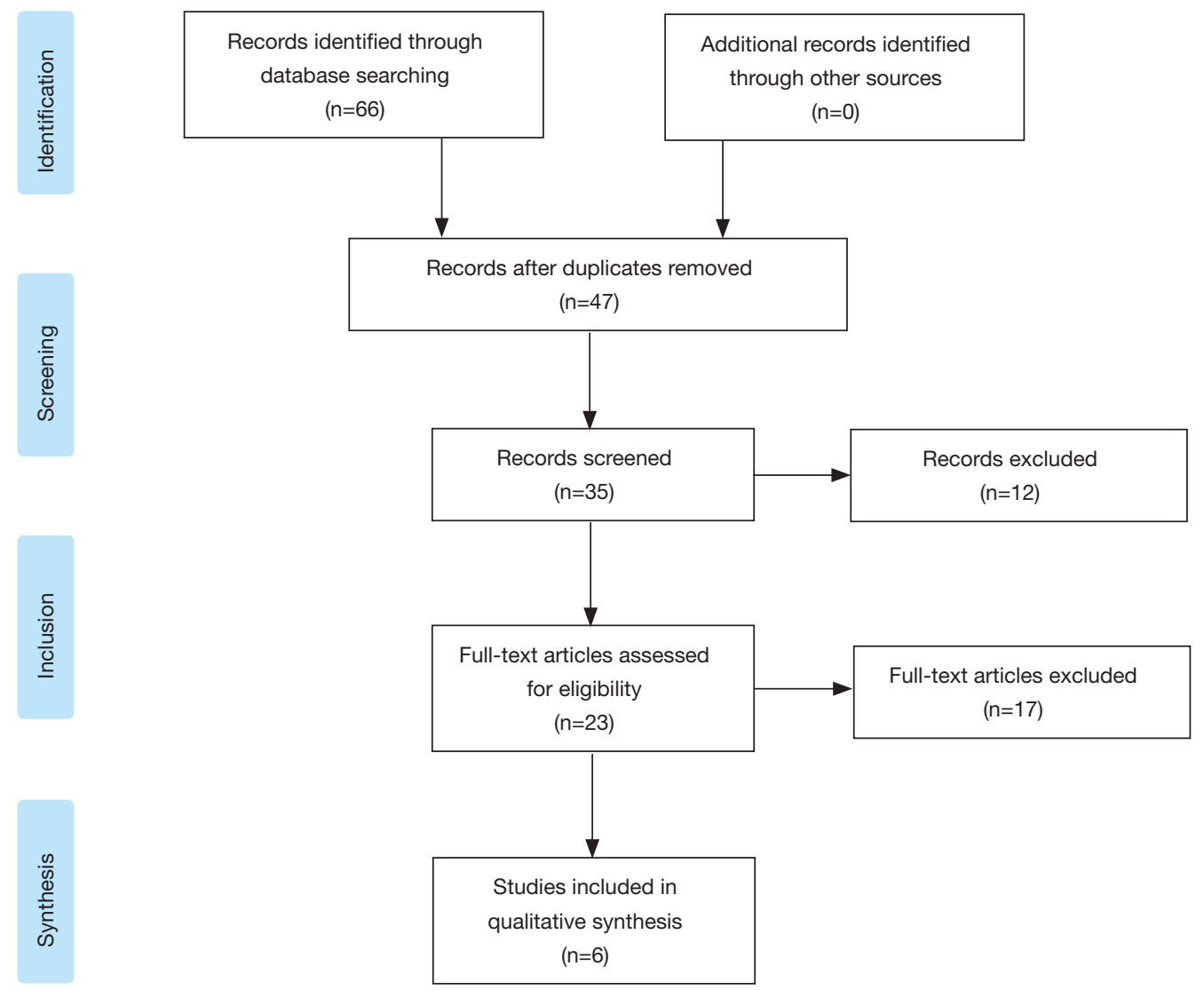

Figure 1 Flow diagram of selection process for articles in this review.

levels were found to be $3.96 \mathrm{ug} / \mathrm{L}$ (range, 0.14 to $11.96 \mathrm{ug} / \mathrm{L}$ ). Chromium levels were reduced by an average of $78 \%$ between maternal and umbilical cord blood. No cobalt or chromium was detected in the umbilical cord blood of three patients.

\section{Comparison to controls}

Two studies compared maternal and fetal blood measurements to control cohorts. In the study by Ziaee et al. (11), maternal blood cobalt and chromium measured 1.39 and $1.28 \mu \mathrm{g} / \mathrm{L}$ in MoM patients $v s$. 0.34 and $0.199 \mu \mathrm{g} / \mathrm{L}$ in the control cohort. Umbilical cord blood concentrations of cobalt and chromium measured 0.839 and $0.378 \mu \mathrm{g} / \mathrm{L}$ in $\mathrm{MoM}$ patients vs. 0.336 and $0.194 \mu \mathrm{g} / \mathrm{L}$ in the control cohort. Novak et al. (9) recorded similarly high measurements in the maternal and fetal blood samples of MoM patients. Maternal cobalt and chromium averaged as low as 0.2 and $0.1 \mathrm{ng} / \mathrm{mL}$ while in the fetal cord blood they averaged 0.15 and $0.09 \mathrm{ng} / \mathrm{mL}$.

\section{Infant outcome}

Out of the 21 infants born to women with MoM implants, 20 were born healthy with no complications. One infant was malformed at birth with craniofacial dysplasia (microphthalmia, microtia), cerebral anomalies, and isthmic aortic stenosis with an open aortic duct, bowel malrotation, a hyperplastic thymus, and flexion contractures of both hands (7). This infant suffered mortality one week postpartum.

\section{Discussion}

Historically, women of childbearing age constituted a considerable portion of younger patients undergoing MoM hip arthroplasty (6). Currently, MoM implant use 


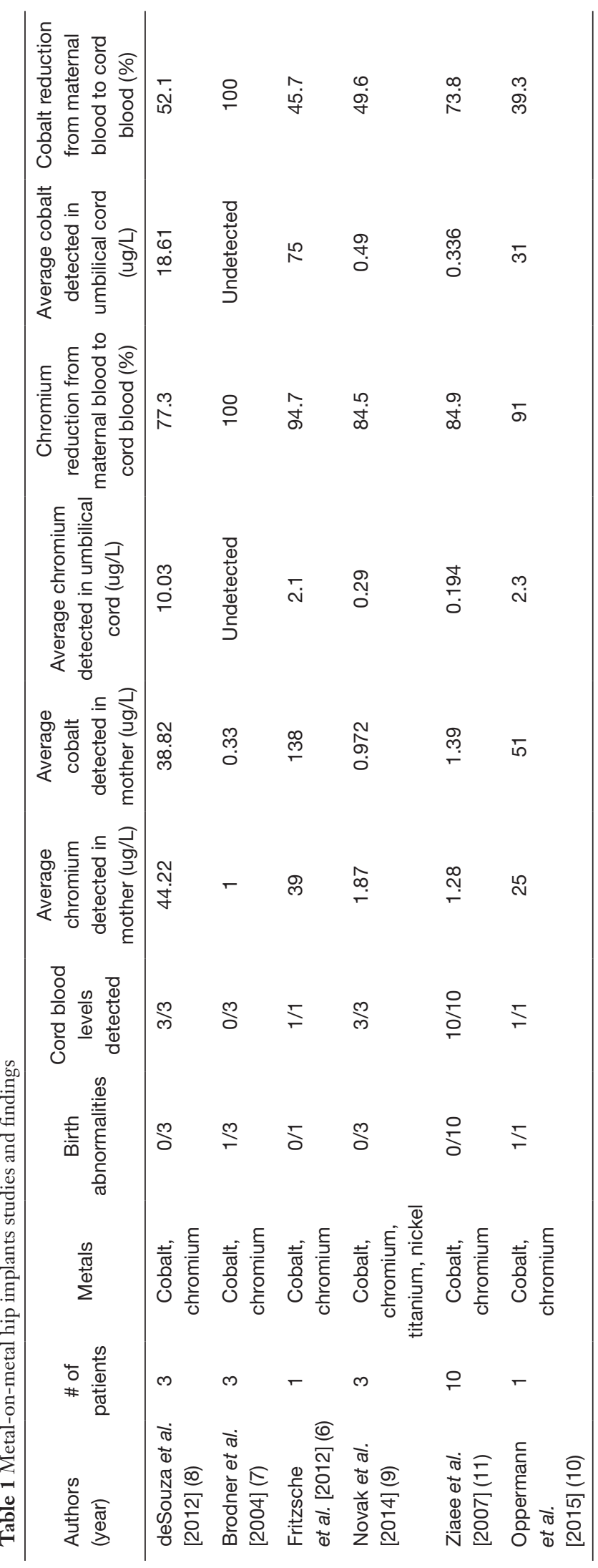

is now obsolete in this patient population due to concerns over the potential effects of elevated metal ion levels on fetal development, as well as the contraindication of some devices in females. At the present time, no evidence exists to definitively recommend for or against the use of MoM hip bearing surfaces in female patients of childbearing age. Our analysis aimed to address this void, through the first and only systematic review focused on the effects of MoM implants in women of childbearing age. Specifically, our review evaluated: (I) the MoM bearing types and ion levels observed; (II); the concentrations of metals in maternal circulation and the umbilical cord; and (III) the presence of abnormalities in the fetus.

The present analysis suggests that elevated levels of circulating cobalt and chromium in pregnant women with MoM implants may cross the placental barrier and lead to elevated levels of these metals in fetal circulation. Detectable levels of cobalt and chromium were found in umbilical cord blood in all cases except 3 (of 3) patients analyzed by Brodner et al. (7). This study used graphite furnace atomic absorption spectrometry, however, which is not as sensitive for metal ion detection compared to other standard analytical techniques (i.e., high-resolution inductively-coupled plasma mass spectrometry). In all of the included studies, authors rose concerns about the higher than normal concentrations of metal ions in the maternal cord blood. However, they failed to demonstrate a clinically relevant complication or abnormality in the fetus.

Despite trans-placental passage of chromium and cobalt, the placenta appears to exert a modulatory effect which reduces their concentration in fetal blood relative to maternal blood. This effect was demonstrated to be greater for chromium than cobalt, although levels of both metals were markedly reduced after placental transfer. It is known that control of substance transfer is a primary function of the placenta (7). Inherently, the modulation of heavy metal ions passing across the placenta likely represents normal physiology, as trace amounts of these ions are necessary for fetal development (11). Several studies have demonstrated the modulatory function of the placenta in transferring metal ions between mother and fetus (13-15). This modulation differs depending on the specific metal traversing the placenta, as the placenta demonstrates an ability to facilitate passage, limit passage, or establish a concentration gradient of specific ions (15). Our analysis supports these known functions of the placenta by demonstrating its ability to limit the transfer of both cobalt and chromium to the fetus. 
Although MoM hip prostheses in pregnant women may lead to elevated chromium and cobalt levels in their offspring, the clinical relevance of these elevations is uncertain. Industrial exposure to cobalt and chromium has been shown to have cardiac, renal, ophthalmic, immunologic, reproductive, and carcinogenic effects (16). However, limited evidence exists to suggest that similar effects are found in hip arthroplasty procedures, where the degree of exposure is lower and the mechanism of exposure is distinctly different (16-19). Reports of adverse local tissue reactions and acute systemic effects associated with ion release from MoM implants exist (20-27), however, the incidence and specific etiology of these reactions or effects remain elusive. Moreover, the long-term effects of chromium and cobalt release from metal prostheses are undetermined.

Our analysis suggests elevated levels of circulating chromium and cobalt in pregnant women with MoM prostheses present no identifiable threat to fetal health. Twenty out of twenty-one infants in the included studies were born healthy, without any noted malformations. As reported by Brodner et al., one infant was born substantially malformed and non-viable. The relationship between this infant's malformalities and the mother's MoM implants may represent simple correlation versus identifiable causation. This specific mother gave birth to three children prior to receiving her MoM implant, two of which were malformed in a similar manner to the infant in the study. These two children were also from the same partner as her final malformed child born during the study, while her healthy child was from a different father (7). Another infant reported by Oppermann et al. was born with mild hypospadias (10), a common birth defect of multifactorial etiology $(10,28)$. Although other studies have found a link between hypospadias and high blood levels of cadmium and lead (29), a similar association has not been demonstrated for chromium or cobalt. Aside from the hypospadias, this infant was otherwise healthy and developed normally.

Our analysis aimed to characterize the effects of MoM hip bearing surfaces and circulating metal ion levels in women of childbearing age, specifically regarding these effects on fetal health. The results of this analysis suggest MoM hip prostheses are likely well-tolerated in women of childbearing age and do not present an identifiable threat to fetal health. Although chromium and cobalt released from MoM implants cross the placental barrier, this process is modulated by specific mechanisms which decrease the amount of ions entering fetal circulation.

Moreover, the presence of metal in umbilical cord blood was not correlated with congenital malformations in the fetus, as none of the infants experienced congenital abnormalities uniquely attributable to the presence of metal. This review was limited by the methodological quality of its inclusion studies, all of which had relatively small sample sizes and did not track mother or infant health over the long term. To our knowledge, however, this analysis represents the most comprehensive investigation to date regarding the safety of MoM implants in women of childbearing age. Future studies should focus on analyzing larger sample populations, and tracking patients over longer periods of time.

\section{Acknowledgments}

None.

\section{Footnote}

Conflicts of Interest: All authors have completed the ICMJE uniform disclosure form (available at http://dx.doi. org/10.21037/atm.2019.07.44). MA Mont reports the following: AAOS: Board or committee member; American Association of Hip and Knee Surgeons: Board or committee member; Cymedica: Paid consultant; DJ Orthopaedics: Paid consultant; Research support; Flexion Therapeutics: Paid consultant; Johnson \& Johnson: Paid consultant; Research support; Fournal of Arthroplasty: Editorial or governing board; Fournal of Knee Surgery: Editorial or governing board; Knee Society: Board or committee member; Medicus Works LLC: Publishing royalties, financial or material support; Microport: IP royalties; National Institutes of Health (NIAMS \& NICHD): Research support; Ongoing Care Solutions: Paid consultant; Research support; Orthopedics: Editorial or governing board; Orthosensor: Paid consultant; Research support; Pacira: Paid consultant; Peerwell: Paid consultant; Stock or stock Options; Performance Dynamics: Paid consultant; Pfizer: Paid consultant; Skye Biologics: Paid consultant; Stryker: IP royalties; Paid consultant; Research support; Surgical Techniques International: Editorial or governing board; TissueGene: Paid consultant, Research support; Up-to Date: Publishing royalties, financial or material support; USMI: Stock or stock Options; Wolters Kluwer Health - Lippincott Williams \& Wilkins: Publishing royalties, financial or material support. 
PJ Brooks reports the following: Smith \& Nephew: Paid consultant; Zimmer: Paid consultant. The other authors have no conflicts of interest to declare.

Ethical Statement: The authors are accountable for all aspects of the work in ensuring that questions related to the accuracy or integrity of any part of the work are appropriately investigated and resolved.

\section{References}

1. Nunley RM, Della Valle CJ, Barrack RL. Is Patient Selection Important for Hip Resurfacing? Clin Orthop Relat Res 2009;467:56-65.

2. Treacy RB, McBryde CW, Pynsent PB. Birmingham hip resurfacing arthroplasty. A minimum follow-up of five years. J Bone Joint Surg Br 2005;87:167-70.

3. MacDonald SJ, Brodner W, Jacobs JJ. A consensus paper on metal ions in metal-on-metal hip arthroplasties. J Arthroplasty 2004;19:12-6.

4. Cohen D. How safe are metal-on-metal hip implants? BMJ 2012;344:e1410.

5. Maffulli N, Del Buono A, Denaro V. Hip artroplasty: A transient reason not to be pregnant. Surgeon 2012;10:347-9.

6. Fritzsche J, Borisch C, Schaefer C. Case report: High chromium and cobalt levels in a pregnant patient with bilateral metal-on-metal hip arthroplasties. Clin Orthop Relat Res 2012;470:2325-31.

7. Brodner W, Grohs JG, Bancher-Todesca D, et al. Does the placenta inhibit the passage of chromium and cobalt after metal-on-metal total hip arthroplasty? J Arthroplasty 2004;19:102-6.

8. deSouza RM, Wallace D, Costa ML, et al. Transplacental passage of metal ions in women with hip resurfacing: no teratogenic effects observed. Hip Int 2012;22:96-9.

9. Novak CC, Hsu AR, Della Valle CJ, et al. Metal ion levels in maternal and placental blood after metal-onmetal total hip arthroplasty. Am J Orthop (Belle Mead NJ) 2014;43:E304-8.

10. Oppermann M, Borisch C, Schaefer C. Hip arthroplasty with high chromium and cobalt blood levels--Case report of a patient followed during pregnancy and lactation period. Reprod Toxicol 2015;53:51-3.

11. Ziaee H, Daniel J, Datta AK, et al. Transplacental transfer of cobalt and chromium in patients with metal-on-metal hip arthroplasty: a controlled study. J Bone Joint Surg Br 2007;89:301-5.
12. Case CP, Ellis L, Turner JC, et al. Development of a routine method for the determination of trace metals in whole blood by magnetic sector inductively coupled plasma mass spectrometry with particular relevance to patients with total hip and knee arthroplasty. Clin Chem 2001;47:275-80.

13. Krachler M, Rossipal E, Micetic-Turk D. Trace element transfer from the mother to the newborn--investigations on triplets of colostrum, maternal and umbilical cord sera. Eur J Clin Nutr 1999;53:486-94.

14. Osman K, Akesson A, Berglund M, et al. Toxic and essential elements in placentas of Swedish women. Clin Biochem 2000;33:131-8.

15. Rossipal E, Krachler M, Li F, et al. Investigation of the transport of trace elements across barriers in humans: studies of placental and mammary transfer. Acta Paediatr 2000;89:1190-5.

16. Keegan GM, Learmonth ID, Case CP. A systematic comparison of the actual, potential, and theoretical health effects of cobalt and chromium exposures from industry and surgical implants. Crit Rev Toxicol 2008;38:645-74.

17. Afolaranmi GA, Tettey J, Meek RM, et al. Release of Chromium from Orthopaedic Arthroplasties. Open Orthop J 2008;2:10-8.

18. Leikin JB, Karydes HC, Whiteley PM, et al. Outpatient toxicology clinic experience of patients with hip implants. Clin Toxicol (Phila) 2013;51:230-6.

19. Finley BL, Monnot AD, Gaffney SH, et al. Dose-response relationships for blood cobalt concentrations and health effects: a review of the literature and application of a biokinetic model. J Toxicol Environ Health B Crit Rev 2012;15:493-523.

20. Urban RM, Jacobs JJ, Tomlinson MJ, et al. Dissemination of wear particles to the liver, spleen, and abdominal lymph nodes of patients with hip or knee replacement. J Bone Joint Surg Am 2000;82:457-76.

21. Watters TS, Eward WC, Hallows RK, et al. Pseudotumor with superimposed periprosthetic infection following metal-on-metal total hip arthroplasty: a case report. J Bone Joint Surg Am 2010;92:1666-9.

22. Willert HG, Buchhorn GH, Fayyazi A, et al. Metalon-metal bearings and hypersensitivity in patients with artificial hip joints. A clinical and histomorphological study. J Bone Joint Surg Am 2005;87:28-36.

23. Hsu AR, Gross CE, Levine BR. Pseudotumor from modular neck corrosion after ceramic-on-polyethylene total hip arthroplasty. Am J Orthop (Belle Mead NJ) 2012;41:422-6. 
24. Tower SS. Arthroprosthetic Cobaltism: Neurological and Cardiac Manifestations in Two Patients with Metal-on-Metal Arthroplasty. J Bone Joint Surg Am 2010;92:2847-51.

25. Mahendra G, Pandit H, Kliskey K, et al. Necrotic and inflammatory changes in metal-on-metal resurfacing hip arthroplasties. Acta Orthop 2009;80:653-9.

26. Williams DH, Greidanus NV, Masri BA, et al. Prevalence of Pseudotumor in Asymptomatic Patients After Metalon-Metal Hip Arthroplasty. J Bone Joint Surg Am

Cite this article as: Samuel LT, Rabin JM, Arnold NR, Munim M, Brooks PJ, Mont MA. Metal-on-metal (MoM) hip implants and pregnancy: are MoM implants good for mom?a systematic review. Ann Transl Med 2019. doi: 10.21037/ atm.2019.07.44
2011;93:2164-71.

27. Oldenburg M, Wegner R, Baur X. Severe cobalt intoxication due to prosthesis wear in repeated total hip arthroplasty. J Arthroplasty 2009;24:825.e15-20.

28. Kalfa N, Philibert P, Baskin LS, et al. Hypospadias: Interactions between environment and genetics. Mol Cell Endocrinol 2011;335:89-95.

29. Johnson AJ, Woon RP, Le Duff MJ, et al. Childhood development after maternal metal-on-metal hip resurfacing. Hip Int 2013;23:181-6. 